\title{
More House Calls by Fewer Physicians
}

\author{
Irene Hamrick, MD
}

Before World War II $40 \%$ of patient visits were conducted in the home. ${ }^{1}$ Since then the number of house calls by physicians had been decreasing until 1998 when payment restructuring improved reimbursement. As the article by Peterson et $\mathrm{al}^{2}$ points out, the number of patients receiving house calls has increased in recent years, yet the number of physicians making house calls has decreased. This may be related to stagnant reimbursements and increasing overhead costs, requiring physicians to see more patients in the clinic with greater "efficiency." Home visits take more time including driving or "windshield time" and performing activities that are routinely done by office staff such as measuring vital signs, uncovering dressings, and drawing blood for laboratory tests. On the other hand, home visits can be conducted with little overhead if providers are added to an already full practice or, as it has become the business model for some practices, provide house calls exclusively. This may explain Peterson et al's ${ }^{2}$ finding that increasing availability of physicians and some providers being designated as "housecall physicians" by their group practice or in their town. Some physicians provide house calls and nursing home care solely with the motto: "have laptop and cell phone, will travel." Such a practice model allows more flexibility, which may be attractive to women with small children. Peterson et al ${ }^{2}$ showed that increasingly more physicians making house calls are women and most recently, in 2006, more than half of providers are female, although the number

From Brody School of Medicine at East Carolina University, Family Medicine, Madison, WI.

Funding: none.

Conflict of interest: none declared.

Corresponding author: Irene Hamrick, MD, University of Wisconsin, Department of Family Medicine, 1100 Delaplaine Court, Madison, WI 53715, (E-mail: ihamrick@wisc.edu).

See Related Article on Page 862. of house calls made by women physicians is lower than that made by men.

As accountable care organizations will manage population health along with its risks, house calls will become increasingly more important. House calls will eliminate ambulance transportation costs to physician offices, which are currently born by Medicaid for eligible patients. By identifying an average of 1.7 new problems compared to a thorough geriatric assessment, ${ }^{3}$ house calls may prevent future problems and improve quality of care. Improved quality, affordability, and patient experience have been shown in the "hospital-at-home" program, ${ }^{4,5}$ where patients requiring hospitalization for problems such as pneumonia, congestive heart failure, chronic obstructive pulmonary disease, or cellulitis are managed at home with daily physician visits, intensive nursing coverage, and other services. More than 9 house calls to a patient have been shown to reduce nursing home admissions, functional decline, and mortality. ${ }^{6}$ A recent study ${ }^{7}$ of patients enrolled in a house call program for 1 year showed a $40 \%$ reduction of hospitalization and $38 \%$ shorter length of stay compared with the prior year. In contrast to consultation, the benefits appear to be due to repeated follow-up, a strength of family medicine. ${ }^{6}$ The implementation of portable diagnostic devices has been thwarted in some settings by the competing interests of hospitals, as in the case of calibrating laboratory test devices. This competition for scarce fee-for-service Medicare dollars would be eliminated by accountable care organizations.

Family medicine residency education requires home visits to a minimum of 2 patients but the requirements are not more specific. Our colleagues in internal medicine are not required to do home visits during their residency education, but a program director survey shows that two thirds included instruction in home care consisting of house calls, lectures, or both. ${ }^{7}$ House call experiences vary widely and it is not known if greater exposure 
during training translates into more home visits in practice.

\section{References}

1. Levine SA, Boal J, Boling PA. Home care. JAMA 2003;290:1203-7.

2. Peterson LE, Landers SH, Bazemore A. Trends in physician house calls to Medicare beneficiaries. J Am Board Fam Med 2012;25: 862-8.

3. Bolin P. The physician's role in home healthcare. New York (NY): Springer; 1997.

4. Leff B, Burton L, Mader SL, Naughton B, Burl J, Inouye SK, et al. Hospital at home: feasibility and outcomes of a program to provide hospital-level care at home for acutely ill older patients. Ann Intern Med 2005;143:798-808.

5. Cryer L, Shannon SB, Van Amsterdam M, Leff B. Costs for 'hospital at home' patients were 19 percent lower, with equal or better outcomes compared to similar inpatients. Health Aff (Millwood) 2012;31: 1237-43.

6. Stuck AE, Egger M, Hammer A, Minder CE, Beck JC. Home visits to prevent nursing home admission and functional decline in elderly people: systematic review and meta-regression analysis. JAMA 2002;287:1022-8.

7. Stoltz CM, Smith LG, Boal JH. Home care training in internal medicine residencies: a national survey. Acad Med 2001;76:181-3. 